\title{
Identification of novel E347Q and G362K amino acid substitutions in HN neutralization epitope and major antigenic difference in novel sub-genotype VIIj isolates
}

\author{
V. MAYAHI, M. ESMAELIZAD* \\ Central Laboratory Department, Razi Vaccine and Serum Research Institute, Agricultural Research, Education and Extension \\ Organization (AREEO), Karaj, Alborz, Iran
}

Received January 24, 2017; revised February 1, 2017; accepted September 26, 2017

\begin{abstract}
Summary. - Hemagglutinin-neuraminidase (HN) protein of Newcastle disease virus (NDV) plays a crucial role in induction of immune response against Newcastle disease infection. Mutation in residues 347 and 362 of $\mathrm{HN}$ linear antigenic site has been identified to be responsible for antigenic variations. Hence we studied antigenic difference between sub-genotype VIIj isolates and vaccine strains by the use of polyclonal serum against LaSota strain in hemagglutination inhibition test. Furthermore, epitope patterns of the isolates under study were analyzed and compared to HN sequences in GenBank. The results demonstrated that new Newcastle disease isolates (Mazandaran and Behshahr) had hemagglutination inhibition (HI) titer three and five, respectively while LaSota strain titer was eight. In addition, observation of sequences and epitope patterns revealed three unique amino acid substitutions (D144N, E347Q and G362K) in HN protein. E347Q and G362K mutations were located in neutralization antigenic site. Thus, we suggest that, these two novel amino acid substitutions in major linear epitope might be responsible for antigenic variation and decrease of HI activity.
\end{abstract}

Keywords: Newcastle disease virus; epitope; amino acid substitution; hemagglutinin-neuraminidase; mutation

\section{Introduction}

Newcastle disease virus (NDV) has been introduced as a causative agent of destructive avian disease. Newcastle disease (ND) effectively results in massive economic losses worldwide (Courtney et al., 2012; Maminiaina et al., 2010; Zhang et al., 2010). This single stranded negative-sense RNA virus, belongs to the Avulavirus genus and the Paramyxoviridae family, comprising of six genes which encode for nucleoprotein (NP), phosphoprotein $(\mathrm{P})$, matrix $(\mathrm{M})$, fusion $(\mathrm{F})$, hemagglutininneuraminidase $(\mathrm{HN})$, and RNA-dependent RNA-polymerase (L) proteins (Munir et al., 2011; Tsunekuni et al., 2010).

*Corresponding author. E-mail: m.esmaelizad@rvsri.ac.ir; phone: +982634570038.

Abbreviations: $\mathrm{HI}=$ hemagglutination inhibition; $\mathrm{HN}=$ hemagglutinin-neuraminidase; ICPI = intracerebral pathogenicity index; $\mathrm{MDT}=$ mean death time; $\mathrm{ND}=$ Newcastle disease $; \mathrm{NDV}=\mathrm{New}-$ castle disease virus; $\mathrm{SPF}=$ specific pathogen-free
Lentogenic, mesogenic and velogenic pathotypes have been identified for ND viurses based on conventional in vivo tests: mean death time (MDT), intracerebral pathogenicity index (ICPI) and intravenous pathogenicity index (IVPI) (Cho et al., 2007; Maminiaina et al., 2010; Wei et al., 2008; Zhang et al., 2011). Three genome sizes have been characterized for ND viruses. The genome length of $15,198 \mathrm{nt}$ is attributed to class I NDVs (non-pathogenic to chickens), while the viruses with 15,186 nt and 15,192 nt length involve both virulent and avirulent pathotypes (class II strains with 18 genotypes and various sub-genotypes) (Wang et al., 2015).

Hemagglutinin-neuraminidase protein is a surface glycoprotein on the envelope of virus particles which causes viruscell fusion facilitation as well as virus attachment to sialic acid receptors, neuraminidase (sialidase) activity, cleavage of sialic acid, and as a result release of virions (Gu et al., 2011; Lam et al., 2011; Wei et al., 2008). A cytoplasmic domain, a transmembrane region, a stalk region and a globular head form HN protein structure (Hu et al., 2010). Neuraminidase 
activity of $\mathrm{HN}$ protein is mediated by receptor-binding site located on the globular head (Hu et al., 2010). Moreover, all of the antigenic sites reside on the globular head domain of HN protein (Hu et al., 2010).

Immunity against ND is induced by multiple factors in addition to HN protein (Cho, 2008a). Several overlapping conformational antigenic sites and one major linear epitope (345 to 353) have been identified in HN protein using monoclonal antibodies (Cho et al., 2008a). Previous studies have confirmed that variation in residue 345 to 353 of $\mathrm{HN}$ protein could result in increase of antigenic differences (Cho et al., 2008b).

In the present study, we focused on molecular characterization of $\mathrm{HN}$ coding sequence of two new virulent sub-genotype VIIj isolates (Mazandaran and Behshahr) (Esmaelizad et al., 2016) from Iran. Epitope prediction and analysis of genetic variations in hemagglutinin-neuraminidase protein of the mentioned isolates were performed and compared to various ND viruses.

\section{Materials and Methods}

Virus isolation and preparation. Virus samples under study (Mazandaran and Behshahr isolates originated from chicken) were isolated from a new outbreak in northern region of Iran in 2015. The viruses were inoculated into the allantoic cavity of 9-day-old specific pathogen-free (SPF) eggs and incubated at $37^{\circ} \mathrm{C}$.

Pathogenicity tests. The pathogenicity of the isolates under study was determined using in vivo tests. Intracerebral pathogenicity index (ICPI) test was performed in day-old SPF chicks by intracerebral injection $(0.05 \mathrm{ml})$ of the allantoic fluid (10-fold dilution). Post-inoculation observations were carried out in birds for eight days. Zero score was attributed to healthy birds, while one and two values were representative of sick and dead birds, respectively. The mean score per bird per observation over the eight-day period was considered as the ICPI value.

Mean death time (MDT) test was performed by inoculation of 9-day-old embryonated SPF eggs. The allantoic fluid was serially diluted 10 -fold, inoculated $\left(0.1 \mathrm{ml}\right.$ of $\left.10^{-7}, 10^{-8}, 10^{-9}\right)$ into the allantoic cavity using a minimum 10 eggs per dilution and incubated at $37^{\circ} \mathrm{C}$. Afterwards, observation of embryo's death was done twice daily for seven days. The mean lethal dose (MLD) was recorded at the highest dilution of embryo's death. The average death time of the eggs inoculated with MLD was taken as MDT.

$H A$ and HI assays. Hemagglutination assay in plates was carried out by mixing $25 \mu \mathrm{l}$ of serially diluted virus, $25 \mu \mathrm{l}$ of PBS, and 50 $\mu \mathrm{l}$ of chicken erythrocytes and incubated at room temperature for $30 \mathrm{~min}$. Hemagglutination inhibition (HI) assay was performed with $25 \mu \mathrm{l}$ of PBS, $25 \mu \mathrm{l}$ of serially diluted polyclonal serum against LaSota strain, and $4 \mathrm{HA}$ units of virus by shaking $20 \mathrm{~min}$ at room temperature. Then $25 \mu$ of chicken erythrocytes were added and the plates were shaken for another $30 \mathrm{~min}$ at room temperature.
Reverse transcription-PCR (RT-PCR) and sequencing. Genomic RNA extraction from infected allantoic fluid was done using High Pure Viral RNA kit (Roche Diagnostic, Germany), according to the manufacturer's instructions. To generate complementary DNA (cDNA) from viral RNA in a total volume of $20 \mu$ reaction mixture, $4 \mu \mathrm{l}$ of $5 \times$ reaction buffer, $2 \mu \mathrm{l}$ dNTPs, $1 \mu \mathrm{l}$ of RNase inhibitor, $2 \mu \mathrm{l}$ of random primers, $1 \mu \mathrm{l}$ M-MuLV enzyme, $5 \mu \mathrm{l}$ of total RNA, and $5 \mu \mathrm{LEPC}$ water were mixed. Reverse transcription was carried out at $25^{\circ} \mathrm{C}$ for $10 \mathrm{~min}, 42^{\circ} \mathrm{C}$ for $60 \mathrm{~min}$, and $70^{\circ} \mathrm{C}$ for $10 \mathrm{~min}$. The complete $\mathrm{HN}$ coding sequence was amplified using specific primers: HF (5'-cgg ggt acc gtc gac aat tca caa cct ccg ttc tac c-3'), HR (5'-ata aga atg cgg ccg cgt cat ctt tga gga tct caa c-3') designed by OLIGO software (Molecular Biology Insights Inc., USA). PCR was conducted in a total volume of $50 \mu \mathrm{l}$ using $10 \times$ reaction buffer $(5 \mu \mathrm{l})$, dNTPs ( $1 \mu \mathrm{l}), \mathrm{MgCl}_{2}(1.5 \mathrm{mmol} / \mathrm{l})$, Pfu DNA polymerase (1 unit), forward and reverse primers (10 pmol of each), cDNA $(2 \mu \mathrm{l})$, and $38.3 \mu \mathrm{l}$ $\mathrm{ddH}_{2} \mathrm{O}$, and performed at $93^{\circ} \mathrm{C}$ for $3 \mathrm{~min}, 35$ cycles of $93^{\circ} \mathrm{C}$ for $1 \mathrm{~min}, 52^{\circ} \mathrm{C}$ for $30 \mathrm{~s}, 72^{\circ} \mathrm{C}$ for $1 \mathrm{~min}$ and $30 \mathrm{~s}$, and a final extension at $72^{\circ} \mathrm{C}$ for $5 \mathrm{~min}$. Purification of amplicons was carried out using High Pure PCR product purification kit (Roche Diagnostic, Germany) following the manufacturer's instructions. Sanger method was used to sequence the purified PCR products in both directions using forward and reverse primers (Macrogen Inc., South Korea).

Amino acid sequence analysis and three dimensional structure prediction. Hemagglutinin-neuraminidase protein sequences of Mazandaran and Behshahr isolates were aligned and compared with NDV sequences (available on GenBank 09/02/2016) using MegAlign software (DNASTAR, USA). The structure of complete coding sequence of HN protein of new Iranian NDV isolates (subgenotype VIIj) was predicted by Swiss model (Biasini et al., 2014). Deep View/ Swiss-Pdb Viewer (v3.7) software (Guex et al., 2009) was used for 3D structure analysis.

Epitope prediction. Epitope prediction of Mazandaran and Behshahr isolates was carried out using Immune epitope database and analysis resource (http://www.iedb.org/). The linear B-cell epitopes were predicted by $\mathrm{HN}$ protein sequence and analyzed.

Recombination analysis. Recombination events in the complete coding sequence of HN gene of Mazandaran and Behshahr isolates were analyzed by RDP4 software (Martin et al., 2015). Four statistical algorithms (RDP (Marin and Rybicki, 2000), GENECONV (Padidam et al., 1999), Maxchi (Smith et al., 1992) and Chimaera (Posada and Crandall, 2001)) were used to define the occurrence of any recombination in the isolates under study.

Accession numbers. The hemagglutinin-neuraminidase gene sequences of Mazandaran and Behshahr isolates used in this study were submitted to GenBank. The coding sequences are found under Acc. Nos. KU938926 (Mazandaran) and KU938925 (Behshahr).

\section{Results}

Biological characterization of the isolates under study was determined by in vivo pathogenicity tests. Mazandaran and 
Table 1. HI titers of polyclonal serum reactivity to the viruses compared to the HI test results from the study of Hu et al. (2010)

\begin{tabular}{|c|c|c|c|}
\hline \multirow[b]{2}{*}{ Virus designation $^{\mathrm{a}}$} & Antibody $^{\mathrm{b}}$ & \multirow[b]{2}{*}{ Virus designation $^{c}$} & \multirow{2}{*}{$\begin{array}{c}\text { Antibody }^{\mathrm{d}} \\
\text { Polyclonal serum against } \\
\text { JS-06/05 strain (E347K) }\end{array}$} \\
\hline & $\begin{array}{c}\text { Polyclonal serum against LaSota } \\
\text { strain }(347 \mathrm{E})\end{array}$ & & \\
\hline Mazandaran & 3 & NDV/ZJ1 & 7 \\
\hline E347Q & & $347 \mathrm{E}$ & \\
\hline Behshahr & 5 & ZJ1HNK & 9 \\
\hline E347Q & & E347K & \\
\hline LaSota & 8 & JSHNK & 9 \\
\hline $347 \mathrm{E}$ & & E347K & \\
\hline V4 & 7 & JSHNE & 8 \\
\hline $347 \mathrm{E}$ & & $347 \mathrm{E}$ & \\
\hline B1 & 7 & & \\
\hline $347 \mathrm{E}$ & & & \\
\hline
\end{tabular}

${ }^{a} \mathrm{ND}$ viruses analyzed in this study. ${ }^{b} \mathrm{HI}$ titers obtained from hemagglutination inhibition test in the present study. ${ }^{\mathrm{C} D V}$ isolates analyzed by Hu et al. (2010). ${ }^{\mathrm{d}} \mathrm{HI}$ test results from the study of $\mathrm{Hu}$ et al. (2010).

Table 2. Amino acid substitutions in residues 144, 347 and 362 of HN protein in a variety of ND viruses

\begin{tabular}{|c|c|c|c|c|c|c|c|c|c|}
\hline \multirow{2}{*}{ Viruses } & \multirow{2}{*}{ Genotype/Class } & \multicolumn{3}{|c|}{ Mutation residues } & \multirow{2}{*}{ Viruses } & \multirow{2}{*}{ Genotype/Class } & \multicolumn{3}{|c|}{ Mutation residues } \\
\hline & & 144 & 347 & 362 & & & 144 & 347 & 362 \\
\hline Iran-Beh & VIIj/II & $\mathrm{N}$ & $\mathrm{Q}$ & $\mathrm{K}$ & $\begin{array}{l}\text { Cormorant/US(CA) /92 } \\
23071 / 1997\end{array}$ & $\mathrm{Va} / \mathrm{II}$ & $\mathrm{D}$ & $\mathrm{E}$ & $\mathrm{G}$ \\
\hline Iran-Maz & VIIj/II & $\mathrm{N}$ & Q & $\mathrm{K}$ & NDV-P05 & $\mathrm{Vb} / \mathrm{II}$ & $\mathrm{D}$ & G & G \\
\hline HB92 Isolate V4 & II/II & $\mathrm{D}$ & $\mathrm{E}$ & G & $\mathrm{JS} / 2 / 98 / \mathrm{Go}$ & $\mathrm{VIe} / \mathrm{II}$ & $\mathrm{D}$ & G & G \\
\hline VG/GA & II/II & $\mathrm{D}$ & E & G & $\begin{array}{l}\text { Pigeon paramyxovirus-1 } \\
\text { IT-227/82 }\end{array}$ & $\mathrm{VIb} / \mathrm{II}$ & $\mathrm{D}$ & $\mathrm{G}$ & G \\
\hline JL-1 & II/II & $\mathrm{D}$ & $\mathrm{E}$ & G & Pigeon/Italy/1166/00 & $\mathrm{VIa} / \mathrm{II}$ & $\mathrm{D}$ & G & G \\
\hline 99-0868lo & $\mathrm{Ia} / \mathrm{II}$ & $\mathrm{D}$ & $\mathrm{E}$ & G & PPMV-1/New York/1984 & $\mathrm{VIb} / \mathrm{II}$ & $\mathrm{D}$ & G & G \\
\hline I-2progenitor (V4 Variant) & $\mathrm{Ia} / \mathrm{II}$ & $\mathrm{D}$ & $\mathrm{E}$ & $\mathrm{G}$ & NDV05-029 & $\mathrm{VIe} / \mathrm{II}$ & $\mathrm{D}$ & $\mathrm{G}$ & $\mathrm{G}$ \\
\hline PHY-LMV42 & $\mathrm{Ia} / \mathrm{II}$ & $\mathrm{D}$ & $\mathrm{E}$ & G & $\mathrm{ZhJ}-3 / 97$ & $\mathrm{VIc} / \mathrm{II}$ & $\mathrm{D}$ & $\mathrm{E}$ & G \\
\hline D3 & $\mathrm{Ib} / \mathrm{II}$ & $\mathrm{D}$ & $\mathrm{E}$ & G & WX-10-07-Pi & $\mathrm{VIa} / \mathrm{II}$ & $\mathrm{D}$ & G & G \\
\hline chicken/N. Ireland/Ulster/67 & $\mathrm{Ib} / \mathrm{II}$ & $\mathrm{D}$ & $\mathrm{E}$ & G & YZ-23-07-Pi & $\mathrm{VIa} / \mathrm{II}$ & $\mathrm{D}$ & $\mathrm{G}$ & G \\
\hline FJ0801 & $\mathrm{Ib} / \mathrm{II}$ & $\mathrm{D}$ & $\mathrm{E}$ & G & $\mathrm{Kr}-102 / 89$ & $\mathrm{VIc} / \mathrm{II}$ & $\mathrm{D}$ & $\mathrm{E}$ & G \\
\hline $02-1334$ & $\mathrm{Ia} / \mathrm{II}$ & $\mathrm{D}$ & $\mathrm{E}$ & G & W4 & $\mathrm{VIa} / \mathrm{II}$ & $\mathrm{D}$ & $\mathrm{G}$ & G \\
\hline $98-1249$ & $\mathrm{Ia} / \mathrm{II}$ & $\mathrm{D}$ & $\mathrm{E}$ & $\mathrm{G}$ & GD/1/98/Go & VIIe/II & $\mathrm{D}$ & $\mathrm{E}$ & $\mathrm{G}$ \\
\hline Mukteswar & III/II & $\mathrm{D}$ & E & $\mathrm{G}$ & $\begin{array}{l}\text { Goose paramyxovirus } \\
\text { SF02 isolate GPV-SF02 }\end{array}$ & VIId/II & $\mathrm{D}$ & $\mathrm{E}$ & $\mathrm{G}$ \\
\hline $\mathrm{JS} / 7 / 05 / \mathrm{Ch}$ & III/II & $\mathrm{D}$ & $\mathrm{E}$ & G & JS02 & VIIf/II & $\mathrm{D}$ & $\mathrm{K}$ & G \\
\hline JS/9/05/Go & III/II & $\mathrm{D}$ & $\mathrm{E}$ & G & SL03 & VIIb/II & $\mathrm{D}$ & $\mathrm{K}$ & $\mathrm{G}$ \\
\hline $\mathrm{JS} / 2 / 05 / \mathrm{Go}$ & III/II & $\mathrm{D}$ & $\mathrm{K}$ & G & SRZ03 & VIIg/II & $\mathrm{D}$ & $\mathrm{K}$ & G \\
\hline $\begin{array}{l}\text { NDV/Mallard/CH/ } \\
\text { HLJ383/06 }\end{array}$ & III/II & $\mathrm{D}$ & $\mathrm{E}$ & G & SWS03 & VIIf/II & $\mathrm{D}$ & $\mathrm{K}$ & $\mathrm{G}$ \\
\hline Italien & IV/II & $\mathrm{D}$ & $\mathrm{E}$ & G & TJ05 & VIId/II & $\mathrm{D}$ & $\mathrm{K}$ & $\mathrm{G}$ \\
\hline Herts/33 & IV/II & $\mathrm{D}$ & $\mathrm{E}$ & $\mathrm{G}$ & SGM01 & VIId/II & $\mathrm{D}$ & $\mathrm{K}$ & $\mathrm{G}$ \\
\hline $\begin{array}{l}\text { Anhinga/ } \\
\text { USA(FL)/44083/93 }\end{array}$ & $\mathrm{V} / \mathrm{II}$ & $\mathrm{D}$ & $\mathrm{E}$ & G & QG/Hebei/07 & VIIg/II & $\mathrm{D}$ & $\mathrm{K}$ & $\mathrm{G}$ \\
\hline
\end{tabular}


Table 2 (continued)

\begin{tabular}{|c|c|c|c|c|c|c|c|c|c|}
\hline \multirow{2}{*}{ Viruses } & \multirow{2}{*}{ Genotype/Class } & \multicolumn{3}{|c|}{ Mutation residues } & \multirow{2}{*}{ Viruses } & \multirow{2}{*}{ Genotype/Class } & \multicolumn{3}{|c|}{ Mutation residues } \\
\hline & & 144 & 347 & 362 & & & 144 & 347 & 362 \\
\hline Chicken/Honduras/15/00 & $\mathrm{Vb} / \mathrm{II}$ & $\mathrm{D}$ & $\mathrm{E}$ & G & NDV/Bali-1/07 & VIIh/II & $\mathrm{D}$ & $\mathrm{E}$ & $\mathrm{E}$ \\
\hline $\begin{array}{l}\text { Gamefowl/ } \\
\text { US(CA)/212676/2002 }\end{array}$ & $\mathrm{Vb} / \mathrm{II}$ & $\mathrm{D}$ & $\mathrm{E}$ & G & $\mathrm{XD} /$ Shandong/08 & VIIg/II & $\mathrm{D}$ & $\mathrm{K}$ & G \\
\hline $\begin{array}{l}\text { Cormorant/ } \\
\text { Canada/98CNN3- } \\
\text { V1125/1998 }\end{array}$ & $\mathrm{Va} / \mathrm{II}$ & $\mathrm{D}$ & $\mathrm{E}$ & G & HN-6-07-Ch & VIId/II & $\mathrm{D}$ & $\mathrm{K}$ & G \\
\hline $\begin{array}{l}\text { Cormorant/ } \\
\text { Canada/95DC2345/1995 }\end{array}$ & $\mathrm{Va} / \mathrm{II}$ & $\mathrm{D}$ & $\mathrm{E}$ & G & HN-7-06-Ch & VIIb/II & $\mathrm{D}$ & $\mathrm{E}$ & G \\
\hline $\begin{array}{l}\text { Cormorant/US(NV)/ } \\
\text { 19529-04(USGS)/2005 }\end{array}$ & $\mathrm{Va} / \mathrm{II}$ & $\mathrm{D}$ & $\mathrm{E}$ & $\mathrm{R}$ & XZ-9-08-Ch & VIIb/II & $\mathrm{D}$ & K & G \\
\hline $\begin{array}{l}\text { Cormorant/US(MN)/92- } \\
40140 / 1992\end{array}$ & $\mathrm{~V} / \mathrm{II}$ & $\mathrm{D}$ & $\mathrm{E}$ & G & YZ-22-07-Os & $\mathrm{VIIb} / \mathrm{II}$ & $\mathrm{D}$ & $\mathrm{E}$ & G \\
\hline $\mathrm{ND} / 03 / 018$ & VIIf/II & $\mathrm{D}$ & G & G & GD1003/2010 & $\mathrm{XII} / \mathrm{II}$ & $\mathrm{D}$ & $\mathrm{D}$ & G \\
\hline Chicken/Gianyar/013/10 & VIIi/II & $\mathrm{D}$ & $\mathrm{E}$ & G & $\begin{array}{l}\text { Chicken/CP/ } \\
\text { Rawalpindi2/2010 }\end{array}$ & XIII/II & $\mathrm{D}$ & $\mathrm{D}$ & $\mathrm{R}$ \\
\hline Chicken/Sragen/014/10 & VIIi/II & $\mathrm{D}$ & $\mathrm{E}$ & G & $\begin{array}{l}\text { Chicken/CP/ } \\
\text { Islamabad2/2010 }\end{array}$ & XIII/II & $\mathrm{D}$ & $\mathrm{D}$ & $\mathrm{R}$ \\
\hline Chicken/bali/020/10 & VIIh/II & $\mathrm{D}$ & $\mathrm{E}$ & $\mathrm{K}$ & $\begin{array}{l}\text { Avian-1532-14-Mauritania } \\
2006\end{array}$ & $\mathrm{XIV} / \mathrm{II}$ & $\mathrm{D}$ & $\mathrm{E}$ & G \\
\hline Egret/China/Guangxi/2011 & VIIh/II & $\mathrm{D}$ & $\mathrm{E}$ & G & $\begin{array}{l}\text { Chicken-2601-Ivory } \\
\text { Coast-2008 }\end{array}$ & $\mathrm{XIV} / \mathrm{II}$ & $\mathrm{D}$ & $\mathrm{E}$ & G \\
\hline QH1 & VIII/II & $\mathrm{D}$ & $\mathrm{E}$ & $\mathrm{R}$ & $\begin{array}{l}\text { Chicken-2602-605-Niger- } \\
2008\end{array}$ & $\mathrm{XIV} / \mathrm{II}$ & $\mathrm{D}$ & $\mathrm{E}$ & G \\
\hline QH4 & VIII/II & $\mathrm{D}$ & $\mathrm{E}$ & $\mathrm{R}$ & $\mathrm{JS} / 1 / 03 / \mathrm{Go}$ & $\mathrm{XV} / \mathrm{II}$ & $\mathrm{D}$ & G & G \\
\hline AF2240 & VIII/II & $\mathrm{D}$ & $\mathrm{E}$ & G & $\mathrm{SD} / 5 / 04 / \mathrm{Go}$ & $\mathrm{XV} / \mathrm{II}$ & $\mathrm{D}$ & G & G \\
\hline F48E9 & IX/II & $\mathrm{D}$ & $\mathrm{E}$ & G & XJ-2/97 & $\mathrm{XV} / \mathrm{II}$ & $\mathrm{D}$ & $\mathrm{E}$ & G \\
\hline $\mathrm{JS} / 1 / 97 / \mathrm{Ch}$ & IX/II & $\mathrm{D}$ & $\mathrm{E}$ & G & $\begin{array}{l}\text { Chicken/Dominican Re- } \\
\text { public (JuanLopez)/499- } \\
31 / 2008\end{array}$ & XVI/II & $\mathrm{D}$ & $\mathrm{E}$ & G \\
\hline F48E8 & IX/II & $\mathrm{D}$ & $\mathrm{E}$ & G & $\begin{array}{l}\text { Chicken-2415-580-Burkina } \\
\text { Faso-2008 }\end{array}$ & XVIIa/II & $\mathrm{D}$ & $\mathrm{D}$ & G \\
\hline $\mathrm{ZJ} / 1 / 86 / \mathrm{Ch}$ & IX/II & $\mathrm{D}$ & $\mathrm{E}$ & G & $\begin{array}{l}\text { Chicken-2415-361-Burkina } \\
\text { Faso-2008 }\end{array}$ & XVIIa/II & $\mathrm{D}$ & $\mathrm{E}$ & G \\
\hline $\begin{array}{l}\text { Northern pintail/ } \\
\text { US }(\mathrm{OH}) / 87-486 / 1987\end{array}$ & $\mathrm{X} / \mathrm{II}$ & $\mathrm{D}$ & $\mathrm{E}$ & G & 2007_Mali_ML029_07 & XVIIa/II & $\mathrm{D}$ & $\mathrm{E}$ & $\mathrm{R}$ \\
\hline $\begin{array}{l}\text { Mallard/US(OH)/04- } \\
411 / 2004\end{array}$ & $\mathrm{X} / \mathrm{II}$ & $\mathrm{D}$ & $\mathrm{E}$ & G & 2008_Mali_ML007_08 & XVIIa/II & $\mathrm{D}$ & $\mathrm{D}$ & G \\
\hline $\begin{array}{l}\text { Mallard/US(MN)/00- } \\
32 / 2000\end{array}$ & $\mathrm{X} / \mathrm{II}$ & $\mathrm{D}$ & $\mathrm{E}$ & G & 2009_Mali_ML008 & XVIIIa/II & $\mathrm{D}$ & $\mathrm{E}$ & G \\
\hline $\begin{array}{l}\text { Mallard/US(MN)/MN00- } \\
39 / 2000\end{array}$ & $\mathrm{X} / \mathrm{II}$ & $\mathrm{D}$ & $\mathrm{E}$ & G & 2008_Mali_ML225_08 & XVIIIa/II & $\mathrm{D}$ & $\mathrm{E}$ & G \\
\hline MG_1992 & $\mathrm{XI} / \mathrm{II}$ & $\mathrm{D}$ & $\mathrm{E}$ & G & 2007_Mali_ML038_07 & XVIIIa/II & $\mathrm{D}$ & $\mathrm{E}$ & G \\
\hline MG_MEOLA_08 & $\mathrm{XI} / \mathrm{II}$ & $\mathrm{D}$ & $\mathrm{E}$ & $\mathrm{E}$ & $\begin{array}{l}\text { NDV/Chicken/Togo/ } \\
\text { AKO18/2009 }\end{array}$ & XVIIIb/II & $\mathrm{D}$ & $\mathrm{E}$ & G \\
\hline MG_725_08 & $\mathrm{XI} / \mathrm{II}$ & $\mathrm{D}$ & $\mathrm{E}$ & G & $\mathrm{Du} / \mathrm{CH} / \mathrm{LZJ} / 068 / 2011$ & $1 / \mathrm{I}$ & $\mathrm{D}$ & $\mathrm{D}$ & $\mathrm{N}$ \\
\hline MG_39_4_08 & $\mathrm{XI} / \mathrm{II}$ & $\mathrm{D}$ & $\mathrm{E}$ & G & $\mathrm{Du} / \mathrm{CH} / \mathrm{LJS} / 215 / 2011$ & $1 / \mathrm{I}$ & $\mathrm{D}$ & $\mathrm{D}$ & $\mathrm{N}$ \\
\hline GD12/2011 & $\mathrm{XII} / \mathrm{II}$ & $\mathrm{D}$ & $\mathrm{D}$ & G & $\mathrm{Du} / \mathrm{CH} / \mathrm{LZJ} / 067 / 2011$ & $1 / \mathrm{I}$ & $\mathrm{D}$ & $\mathrm{D}$ & $\mathrm{N}$ \\
\hline GD17/2011 & $\mathrm{XII} / \mathrm{II}$ & $\mathrm{D}$ & $\mathrm{D}$ & G & $\mathrm{Du} / \mathrm{CH} / \mathrm{LJS} / 016 / 2011$ & $1 / \mathrm{I}$ & $\mathrm{D}$ & $\mathrm{D}$ & $\mathrm{N}$ \\
\hline GD20/2011 & $\mathrm{XII} / \mathrm{II}$ & $\mathrm{D}$ & $\mathrm{D}$ & G & J17-13 & $3 / \mathrm{I}$ & $\mathrm{D}$ & $\mathrm{D}$ & $\mathrm{N}$ \\
\hline Poultry/Peru/1918-03/2008 & $\mathrm{XII} / \mathrm{II}$ & $\mathrm{D}$ & $\mathrm{E}$ & G & $\mathrm{J} 72-13$ & $3 / \mathrm{I}$ & $\mathrm{D}$ & $\mathrm{D}$ & $\mathrm{N}$ \\
\hline GD450/2011 & $\mathrm{XII} / \mathrm{II}$ & $\mathrm{D}$ & $\mathrm{D}$ & G & J55-13 & $3 / \mathrm{I}$ & $\mathrm{D}$ & $\mathrm{D}$ & $\mathrm{N}$ \\
\hline La Sota Strain & II/II & $\mathrm{D}$ & E & G & J77-13 & $3 / \mathrm{I}$ & $\mathrm{D}$ & $\mathrm{D}$ & $\mathrm{N}$ \\
\hline B1 & $\mathrm{II} / \mathrm{II}$ & $\mathrm{D}$ & $\mathrm{E}$ & G & & & & & \\
\hline
\end{tabular}


Behshahr isolates showed similar ICPI value of 1.8 and MDT of $72 \mathrm{~h}$. Furthermore, in our previous study related to F gene sequence analysis of sub-genotype VIIj isolates (Esmaelizad et al., 2016), we showed that fusion protein cleavage site ${ }^{112} \mathrm{RRQKRF}{ }^{117}$ was same for both Iranian NDV isolates. Thus, values of pathogenicity indexes and isolates' typical cleavage site suggested that the viruses were virulent.

HI titers of the isolates under study in addition to LaSota, V4 and B1 strains were obtained using polyclonal serum against LaSota strain. According to the results HI titers of polyclonal antibody to Mazandaran and Behshahr isolates were three and five, respectively which were lower than in vaccine strains (HI titer of LaSota strain was eight). Since both Iranian isolates carry E347Q mutation, the major HI titer difference indicated that other mutations or epitopes may be associated with the mentioned amino acid substitution in order to affect antibody/antigen reaction. HI titers of the studied viruses are shown in Table 1.

The phylogenetic analysis of complete coding sequence of $\mathrm{F}$ gene related to the isolates under study revealed that Mazandaran and Behshahr isolates belong to the novel sub-genotype VIIj in class II NDVs (Esmaelizad, 2016). In the present study, we analyzed $\mathrm{HN}$ amino acid sequence of 111 NDV isolates (available on GenBank 09/02/2016). The multiple alignments of viruses of class I and class II (genotypes I-XVIII) confirmed the first report of three amino acid substitutions (D144N, E347Q, G362K) in HN sequence of Mazandaran and Behshahr isolates. A BLAST search among all the NDV amino acid sequences (available on GenBank 09/02/2016) also verified the novelty of our results. Table 2 indicates the amino acid changes of $111 \mathrm{ND}$ viruses in

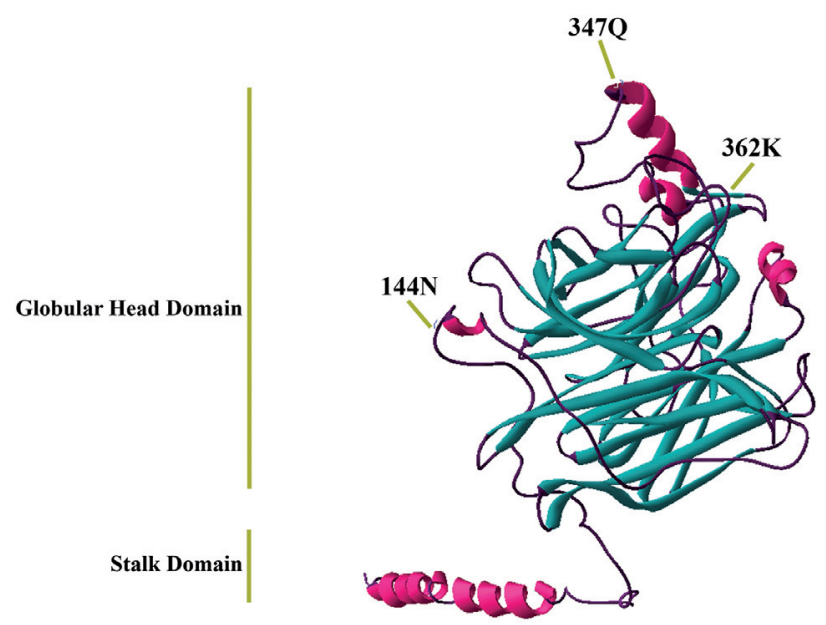

Fig. 1

Three dimensional structure of NDV Behshahr isolate with amino acid substitutions D144N, E347Q and G362K located on the globular head domain of $\mathrm{HN}$ protein residues 144, 347 and 362 . The $\mathrm{HN}$ three dimensional (3D) structure of Behshahr isolate was predicted, and the variable residues (HN: 144, 347, 362) were located on the peptide. Structure analysis indicates that the specific amino acid changes are located on the globular head domain of $\mathrm{HN}$ protein (Fig. 1).

The linear B-cell epitopes of HN based on amino acid sequence of Mazandaran and Behshahr viruses were predicted using http://www.iedb.org/. Several linear epitopes were introduced by B-cell epitope prediction tool (data not shown). The unique mutations (E347Q, G362K) were located on the major linear epitope of HN. Mutation in the mentioned epitope and specifically the residues 347 and 362 are responsible for antigenic variation.

The occurrence of recombination events was analyzed in $\mathrm{HN}$ sequence of the isolates under study. The results indicate that Mazandaran and Behshahr isolates are not recombinant viruses (data not shown).

\section{Discussion}

To diagnose ND, Newcastle disease virus presence must be proved by isolation from SPF eggs or by serological tests (Miller et al., 2010). Hemaglutination inhibition test is broadly performed to detect antigens by repression of NDV HA activity using ND-positive serum (Alexander, 2003). All NDVs analyzed in this study belong to serotype 1 what was confirmed by polyclonal antibodies that did not indicate any antigenic variations, while the specific set of monoclonal antibodies has been regarded as appropriate for detection of variant epitopes (Hu et al., 2010).

Hemagglutination-neuraminidase protein which is a key factor for induction of immunity against NDV carries several conformational antigenic sites and a major linear neutralization epitope (Cho et al., 2008a; Hu et al., 2010). According to published studies, linear epitope of HN (residues 345 to 353) determines antigenic difference in ND viruses, more specifically mutation in $347 \mathrm{E}$ protects the virus from the neutralization (Cho et al., 2008b; Zhu et al., 2016). Amino acid substitution in $\mathrm{HN}$ residue 347 (E347K) has been characterized in genotype VII viruses in Asia. Multiple NDV VIId sub-genotypes of Korea possess the mentioned mutation in $\mathrm{HN}$ protein, which results in virus protection from neutralization caused by specific MAb (Cho et al., 2008a,b). Hemagglutinin-neuraminidase linear epitope of Chinese virulent NDV isolates (sub-genotype VIId) has been also observed, reporting E347K and E347G variations (Hu et al., 2010; Zhu et al., 2016). Moreover, lower antigenic relationship between vaccine strain $(347 \mathrm{E} / \mathrm{G})$ and Chinese isolates carrying E347K substitution proved by cross-neutralization tests has been reported (Zhu et al., 2016). In the present study, the isolates Mazandaran and Behshahr which we 
have reported to be virulent sub-genotype VIIj in class II NDVs, share HI titers of three and five respectively. HI test has been carried out using polyclonal serum against LaSota strain, and the results are in concordance with a study in 2010 which describes that polyclonal serum against JS-06/05 isolate (E347K) added to the isolates sharing the same substitution resulted in higher HI than with NDV/ZJ1 isolate (347E) (Hu et al., 2010). Therefore, data obtained from our $\mathrm{HI}$ assay suggest that antigenic relatedness of Iranian isolates with vaccine strain is also very low. The study of $\mathrm{Hu}$ (2010) also suggests that mutation in residue 347 affects the HI titers. However, our data indicate some discrepancy, since HI with polyclonal serum against LaSota strain to Mazandaran and Behshahr isolates is three and five, respectively which is lower than to LaSota strain (eight). Furthermore, both Iranian isolates share E347Q mutation but their HI titers are different, which might be explained by another residue substitution involved. As other published data suggest, there might be another continuous antigenic site since reactivity of sheep antiserum against residues of 355 to 375 of HN protein occurred (Cho et al., 2008b). Involvement of residue 362 in antigenic difference is also suggested, as both amino acid positions 347 and 362 are located in receptor-binding pocket. Strains with mutations in both sites (E347K/G362A, E347K/G362R) have been recognized as co-variant viruses (Cho et al., 2008b; Zhu et al., 2016). Our results also demonstrate the unique mutations E347Q and G362K in both Mazandaran and Behshahr isolates. The unique amino acid substitutions in our study (residues 347 and 362) explain the major differences in HI test results. Moreover, the mentioned co-variation in the isolates under study may affect the polyclonal serum reactivity to Mazandaran and Behshahr isolates, and also involvement in antigenic variations. Furthermore, we suggest that other epitopes could also be responsible for antibody/antigen reactions in $\mathrm{HI}$ test, as both Iranian isolates share the same co-variation with different HI titers. A study by Zhu et al. (2016) has shown the unsuccessful vaccination of chickens infected with variant isolates (E347K) using LaSota strain. In their results, mortality and morbidity has stopped, but vaccine strain has not been able to inhibit virus shedding (Zhu et al., 2016). Since genotype VII ND viruses are predominant in Asia, Middle East and South America with their broad genetic variations (Diel et al., 2012), vaccination programs with vaccine strains may not be efficient to protect poultry against ND outbreaks in the mentioned regions (Zhu et al., 2016). In addition, new outbreaks in Iran since 2015 (sub-genotype VIIj) share novel amino acid mutations in HN linear epitope. Thus, we suggest further studies should be carried out on the subject of vaccination of chickens challenged with the isolates under study (new ND outbreak in Iran), as the unique mutations in neutralization epitope of $\mathrm{HN}$ (E347Q and G362K) results in antigenic variations and may affect vaccination.
In conclusion, we have studied the complete coding sequence of HN protein in new ND outbreak in north of Iran. Our data has confirmed the first report of three specific amino acid changes (residues 144, 347 and 362) in globular head domain of $\mathrm{HN}$ protein in the isolates under study. We also introduce two novel E347Q and G362K co-variations (located in linear epitope of HN protein) which cause antigenic difference among ND viruses. We have also indicated the low antigenic relationship of the isolates under study with vaccine strain due to $\mathrm{HI}$ titers. This may result in ineffective vaccination of poultry when infected by Mazandaran and Behshahr isolates (sub-genotype VIIj). Therefore, further investigations should be done in order to determine the role of the reported mutations in vaccination.

Acknowledgement. This study was supported by grant No. 2-1818-94129 Razi Vaccine and Serum Research Institute.

\section{References}

Alexander DJ (2003): Newcastle disease and other avian paramyxoviridae infections. In Saif YM (Eds): Diseases of Poultry. Vol. 7, Iowa State Press, Ames, pp. 63-80.

Biasini M, Bienert S, Waterhouse A, Arnold K, Studer G, Schmidt T, Kiefer F, Cassarino TG, Bertoni M, Bordoli L, Schwede T (2014): SWISS-MODEL: modeling protein tertiary and quaternary structure using evolutionary information. Nuc. Acids Res. W1, W252-258. https://doi.org/10.1093/nar/gku340

Cho SH, Kim SJ, Kwon HJ (2007): Genomic sequence of an antigenic variant Newcastle disease virus isolated in Korea. Virus Genes 35, 293-302. https://doi.org/10.1007/s11262$\underline{007-0078-\mathrm{Z}}$

Cho SH, Kwon HJ, Kim TE, Kim JH, Yoo HS, Park MH, Park YH, Kim SJ (2008a): Characterization of a recombinant Newcastle disease virus vaccine strain. Clin. Vaccine Immunol. 15, 1572-1579. https://doi.org/10.1128/CVI.00156-08

Cho SH, Kwon HJ, Kim TE, Kim JH, Yoo HS, Kim SJ (2008b): Variation of a Newcastle disease virus hemagglutininneuraminidase linear epitope. J. Clin. Microbiol. 46, 1541-1544. https://doi.org/10.1128/JCM.00187-08

Courtney SC, Gomez D, Susta L, Hines N, Pedersen JC, Miller PJ, Afonso CL (2012): Complete genome sequencing of a novel Newcastle disease virus isolate circulating in layer chickens in the Dominican Republic. J. Virol. 86, 9550. https://doi.org/10.1128/JVI.01491-12

Diel DG, da Silva LHA, Liu H, Wang Z, Miller PJ, Afonso CL (2012): Genetic diversity of avian paramyxovirus type 1: proposal for a unified nomenclature and classification system of Newcastle disease virus genotypes. Infect. Genet. Evol. 12, 1770-1779. https://doi.org/10.1016/j. meegid.2012.07.012

Esmaelizad M, Mayahi V, Pashaei M, Goudarzi H (2017): Identification of novel Newcastle disease virus sub-genotype VII-(j) based on the fusion protein. Arch. Virol. 162, 971-978. https://doi.org/10.1007/s00705-016-3189-9 
Gu M, Liu W, Xu L, Cao Y, Yao C, Hu S, Liu X (2011): Positive selection in the hemagglutinin-neuraminidase gene of Newcastle disease virus and its effect on vaccine efficacy. Virol. J. 8, 150. https://doi.org/10.1186/1743-422X-8-150

Guex N, Peitsch MC, Schwede T (2009): Automated comparative protein structure modeling with SWISS-MODEL and Swiss-Pdb Viewer: A historical perspective. Electrophoresis 30, S162-173. https://doi.org/10.1002/ elps.200900140

Hu S, Wang T, Liu Y, Meng C, Wang X, Wu Y, Liu X (2010): Identification of a variable epitope on the Newcastle disease virus hemagglutinin-neuraminidase protein. Vet. Microbiol. 140, 92-97. https://doi.org/10.1016/j. vetmic.2009.07.029

Lam HY, Yeap SK, Rasoli M, Omar AR, Yusoff K, Suraini AA, Alitheen NB (2011): Safety and clinical usage of Newcastle disease virus in cancer therapy. J. Biomed. Biotechnol. 2011, 718710. https://doi.org/10.1155/2011/718710

Maminiaina OF, Gil P, Briand FX, Albina E, Keita D, Rasamoelina Andriamanivo H, Chevalier V, Lancelot R, Martinez D, Rakotondravao R, Rajaonarison JJ, Koko M, Andriantsimahavandy AA, Jestin V, Servan de Almeida R (2010): Newcastle disease virus in Madagascar: Identification of an original genotype possibly deriving from a died out ancestor of genotype IV. PloS One 5, e13987. https://doi. org/10.1371/journal.pone.0013987

Martin DP, Murrell B, Golden M, Khoosal A, Muhire B (2015): RDP4: Detection and analysis of recombination patterns in virus genomes. Virus Evol. 1, 1-5. https://doi. org/10.1093/ve/vev003

Martin D, Rybicki E (2000): RDP: detection of recombination amongst aligned sequences. Bioinform. 16, 562-563. https://doi.org/10.1093/bioinformatics/16.6.562

Miller PJ, Decanini EL, Afonso CL (2010): Newcastle disease: Evolution of genotypes and the related diagnostic challenges. Infect. Genet. Evol. 10, 26-35. https://doi.org/10.1016/j. meegid.2009.09.012

Munir M, Linde AM, Zohari S, Stahl K, Baule C, Engstrom B, M Renstrom LH, Berg M (2011): Whole genome sequencing and characterization of a virulent Newcastle disease virus isolated from an outbreak in Sweden. Virus Genes 43, 261-271. https://doi.org/10.1007/s11262-011-0636-2

Padidam M, Sawyer S, Fauquet CM (1999): Possible emergence of new geminiviruses by frequent recombination. Virology 265, 218-225. https://doi.org/10.1006/ viro.1999.0056

Posada D, Crandall KA (2001): Evaluation of methods for detecting recombination from DNA sequences: Computer simulations. Proc. Natl. Acad. Sci. USA 98, 13757-13762. https:// doi.org/10.1073/pnas.241370698

Smith JM (1992): Analyzing the mosaic structure of genes. J. Mol. Evol. 34, 126-129. https://doi.org/10.1007/BF00182389

Tsunekuni R, Ito H, Otsuki K, Kida H, Ito T (2010): Genetic comparisons between lentogenic Newcastle disease virus isolated from waterfowl and velogenic variants. Virus Genes 40, 252-255. https://doi.org/10.1007/s11262-009 -0427-1

Wang J, Liu H, Liu W, Zheng D, Zhao Y, Li Y, Wang Y, Ge S, Lv Y, Zuo Y, Yu S, Wang Z (2015): Genomic characterizations of six pigeon Paramyxovirus type 1 viruses isolated from live bird markets in China during 2011 to 2013. PloS One 10, e0124261. https://doi.org/10.1371/journal. pone. 0124261

Wei D, Yang B, Li YL, Xue CF, Chen ZN, Bian H (2008): Characterization of the genome sequence of an oncolytic Newcastle disease virus strain Italien. Virus Res. 135, 312-319. https://doi.org/10.1016/j.virusres.2008.03.003

Zhang R, Wang X, Su J, Zhao J, Zhang G (2010): Isolation and analysis of two naturally-occurring multi recombination Newcastle disease viruses in China. Virus Res. 151, 45-53. https://doi.org/10.1016/j.virusres.2010.03.015

Zhang S, Zhao AL, Wang AX, Zhang D, Zhao J, Zhang G (2011): Serologic and virologic survey for evidence of infection with velogenic Newcastle disease virus in Chinese duck farms. Avian Dis. 55, 476-479. https://doi.org/10.1637/9649010611-ResNote.1

Zhu J, Hu S, Xu H, Liu J, Zhao Z, Wang X, Liu X (2016): Characterization of virulent Newcastle disease viruses from vaccinated chicken flocks in Eastern China. BMC Vet. Res. 12, 113. https://doi.org/10.1186/s12917-016-0732-6 